\title{
PRESENCIAL E VIRTUAL: O EXTRAPOLAR DE FRONTEIRAS FÍSICAS E DIGITAIS
}

\author{
PRESENTIAL AND VIRTUAL: THE EXTRAPOLATION OF PHYSICAL AND \\ DIGITAL BOUNDARIES
}

\section{PRESENCIAL Y VIRTUAL: EL EXTRAPOLAR DE LAS FRONTERAS FÍSICAS Y DIGITALES}

\author{
Sandra Sausen $^{1}$ (D) \\ Ettiène Cordeiro Guérios ${ }^{2}$
}

\begin{abstract}
RESUMO
Ao atentarmos para o contexto educacional contemporâneo, ponderamos sobre propostas de integração das Tecnologias Digitais de Informação e Comunicação (TDIC) nas práticas pedagógicas. Assim, podemos considerar a presença de atividades virtuais na composição das aulas nos cursos presenciais que formam professores e que ensinam Matemática, fato que nos leva a conjecturar sobre a essencialidade do uso dessas tecnologias e de ambientes virtuais [de aprendizagem] na formação continuada dos professores formadores desses futuros professores. Diante do exposto, o objetivo principal desse texto é investigar que tendência, convergência e complementaridade apresentam as pesquisas stricto sensu nos programas brasileiros de pós-graduação tendo como pano de fundo as TDIC e os ambientes virtuais [de aprendizagem]. Para este fim, realizamos buscas e análises de pesquisas, stricto sensu, disponíveis no Catálogo de teses e dissertações da CAPES e na Biblioteca Digital Brasileira de Teses e Dissertações (BDTD). Concluímos que as pesquisas encontradas apresentaram tendência, convergência e complementaridade, e que atividade, sentido e prazer são termos da equação pedagógica com necessidade de desenvolvimento de uma cultura de formação.
\end{abstract}

Palavras-chave: Formação de professores formadores. TDIC. Ambientes Virtuais [de aprendizagem]. Ensino de Matemática. Interlocução presencial e virtual.

\begin{abstract}
Paying attention to the contemporary educational context, we considered proposals for the integration of Digital Information and Communication Technologies (TDIC) in pedagogical practices. Thus, one can consider the presence of virtual activities in the composition of classes in the classroom courses that train teachers and teach Mathematics, a fact that leads us to conjecture about the essentiality of the use of these technologies and virtual [learning] environments in the continuing education of the teachertrainers of these future teachers. In view of the above, the main objective of this text is to investigate what tendency, convergence and complementarity present stricto sensu research in Brazilian graduate programs, against the background of TDIC and virtual [learning] environments. To this end, searches

\footnotetext{
${ }^{1}$ Doutoranda no Programa de Pós-Graduação em Educação pela Universidade Federal do Paraná (PPGE/UFPR). Professora de Matemática na Educação Básica - Secretaria de Estado da Educação e do Esporte (SEED), União da Vitória, Paraná, Brasil. Rua: Joaquim Távora, 633, União da Vitória, Paraná, Brasil. CEP: 84600-472. E-mail: sansausen@gmail.com.

${ }^{2}$ Doutorado em Educação Matemática pela Universidade Estadual de Campinas (UNICAMP). Professora Programa de Pós-Graduação em Educação (Acadêmico) e Programa de Pós-Graduação em Educação: Teoria e Prática de Ensino (Profissional) da Universidade Federal do Paraná (UFPR), Curitiba, Paraná, Brasil. Endereço: Rua Francisco Rocha 1800, AP. 1401, Curitiba, Paraná, Brasil. CEP 80.730-390. E-mail: ettiene@ufpr.br.
} 
and analyses of stricto sensu research were carried out, available in the Catalogue of theses and dissertations of CAPES and of the Brazilian Digital Library of Theses and Dissertations (BDTD). We conclude that the research found showed a tendency, convergence and complementarity, and that activity, meaning and pleasure are terms of the pedagogical equation with the need to develop a culture of training.

Keywords: Formation of teacher educators. TDIC. Virtual environments [for learning]. Mathematics teaching. Face-to-face and virtual dialogue.

\section{RESUMEN}

Teniendo en cuenta el contexto educativo contemporáneo, analizamos propuestas para la integración de las Tecnologías Digitales de Información y la Comunicación (TDIC) en las prácticas pedagógicas. Así, se puede considerar la presencia de actividades virtuales en la composición de las clases en los cursos presenciales de formación de profesores y que enseñan Matemáticas, hecho que nos lleva a conjeturar sobre la esencialidad del uso de estas tecnologías y ambientes virtuales [de aprendizaje] en formación continua docente de los que forman a estos futuros profesores. Ante lo expuesto anteriormente, el objetivo principal de este texto es investigar qué tendencia, convergencia y complementariedad están presentes en la investigación stricto sensu en los programas de posgrado brasileños en el contexto de TDIC y ambientes virtuales [de aprendizaje]. Para ello, se realizaron búsquedas y análisis de investigaciones stricto sensu, disponibles en el catálogo de tesis y disertaciones CAPES y en la Biblioteca Digital Brasileña de Tesis y Disertaciones (BDTD). Se concluye que las investigaciones encontradas, presentaron tendencia, convergencia y complementariedad y que actividad, sentido y placer son términos de la ecuación pedagógica con la necesidad de desarrollo de una cultura formativa.

Palabras clave: Formación de formadores docentes. TDIC. Ambientes virtuales [de aprendizaje]. Enseñanza de Matemáticas. Diálogo presencial y virtual.

\section{INTRODUÇÃO}

A discussão sobre Tecnologias Digitais de Informação e Comunicação (TDIC) no meio educativo atinge, atualmente, seu ápice devido às transformações pedagógicas impostas pela pandemia que nos assola. Há tempos tal discussão está em pauta e, no momento, diferentes abordagens têm sido registradas. Abordar a perspectiva da formação de professores formadores de professores que ensinam Matemática na modalidade presencial de ensino é um desafio a que nos propusemos, em pesquisa de doutorado ${ }^{3}$, cujo objetivo foi investigar possibilidades de interação e mobilização de conhecimentos matemáticos, pedagógicos, tecnológicos e suas intersecções, em um curso on-line de formação continuada. O foco específico foi a formação dos professores formadores de Curso de Formação de Docentes (antigo Magistério), de Licenciatura em Matemática e em Pedagogia, entrelaçada ao uso de TDIC e de Ambientes

\footnotetext{
${ }^{3}$ Desenvolvida no Programa de Pós-Graduação em Educação da Universidade Federal do Paraná (PPGE/UFPR), no período 2017-2020.
} 
Virtuais [de Aprendizagem] ${ }^{4}$. A potência de atividades virtuais na composição de aulas em cursos presenciais foi a tônica e conjecturamos sobre a essencialidade da integração das TDIC nas práticas pedagógicas.

O presente artigo amplia a discussão com o objetivo de descortinar tendências, convergências e complementaridade que pesquisas stricto sensu dos programas brasileiros de pós-graduação apresentam, tendo como pano de fundo as TDIC e os ambientes virtuais [de aprendizagem]. A perspectiva de formação que adotamos é a de um processo singular e dinâmico que ocorre na interface do desenvolvimento pessoal e profissional de cada professor, considerando-se as peculiaridades do contexto histórico em que acontece.

Dentre os tantos olhares, estudos e pesquisas com foco nessa temática, mencionamos Tardif, Lessard e Lahaye (1991) que abordam os saberes docentes, focando naqueles oriundos da formação profissional, os saberes das disciplinas, os saberes curriculares e os saberes da experiência. Guérios (2002), que busca compreender como professores se constituem profissionalmente em pensamentos, ações e saberes em espaços de formação e prática docente. Também Larrosa (2011), que nos abrilhanta com o conceito de experiência, dentre outros.

Assumimos, metodologicamente, a pesquisa bibliográfica (FIORENTINI e LORENZATO, 2006; KOLLER, COUTO e HOHENDORFF, 2014), com a finalidade de desenhar um panorama da pesquisa stricto sensu na área de Educação. O corpus investigativo foi constituído por pesquisas stricto sensu, disponíveis no Catálogo de Teses e Dissertações da CAPES e na Biblioteca Digital Brasileira de Teses e Dissertações (BDTD). O foco central esteve na formação dos formadores de professores que ensinam Matemática e o uso de TDIC e de ambientes virtuais [de aprendizagem].

Respaldamo-nos na afirmação de Moran (2002, s. p.) que nos é provocativa, instigante e nos faz extrapolar fronteiras ao pensarmos sobre a formação de professores: "[...] o presencial se virtualiza e a distância se presencializa". Temos a crença de que se este dizer for verdadeiro em circunstância didática em que recursos disponíveis em ambientes virtuais sejam utilizados na formação de professores, então, como corolário podemos aludir que o espaço de trocas entre professores e conhecimento curricular se estende além do espaço físico da sala de aula, pois de

\footnotetext{
${ }^{4}$ Em 2011, tecemos o termo Ambiente Virtual [de Aprendizagem] e o utilizamos quando não podemos afirmar precisamente se o uso que foi feito do espaço virtual caracterizou apenas Ambiente Virtual (AV), ou se nesse espaço aconteceu efetivo(s) processo(s) de ensino e de aprendizagem (SAUSEN, 2011). Todavia, temos sempre a perspectiva de que o uso que se fez ou que se está fazendo, caracterize Ambiente Virtual de Aprendizagem. 
acordo com Moran (2004, s. p.), as tecnologias possibilitam “[...] aprender estando juntos em lugares distantes, sem precisarmos estar sempre juntos numa sala para que isso aconteça."

Com o advento das tecnologias surgiu uma nova maneira de ver e apreender o mundo. No processo educacional elas possibilitam novas formas de construção do conhecimento, de ensinar e de aprender, cujo avanço foi antecipado com o advento da Covid 19, fato este que torna o estudo desta temática atual e pertinente.

A partir do exposto, salientamos que nosso foco são as TDIC, pois com amparo no uso da internet torna-se possível o uso de ambientes virtuais [de aprendizagem]. Em Sausen (2011, p. 19) há a preocupação quanto à distinção do uso dos termos "ambientes virtuais" e "ambientes virtuais de aprendizagem" quando afirma que "[...] ao fazer referência a ambientes virtuais alude-se à ideia de espaços desenvolvidos através de recursos computacionais que podem amparar (ou não) processos de ensino e de aprendizagem por meio do uso das TIC via Web." A autora recorre a Almeida (2003) para dizer que o que irá caracterizá-lo como um ambiente virtual de aprendizagem (AVA) é o fato de permitir “[...] integrar múltiplas mídias, linguagem e recursos, apresentar informações de maneira organizada, desenvolver interações entre pessoas e objetos de conhecimento, elaborar e socializar produções tendo em vista atingir determinados objetivos" (ALMEIDA, 2003, p. 331). Na continuidade do texto, trazemos o caminho trilhado e alguns apontamentos.

\section{A FORMAÇÃO DE FORMADORES DE PROFESSORES QUE ENSINAM MATEMÁTICA E O USO DE TDIC E DE AMBIENTES VIRTUAIS [DE APRENDIZAGEM]: TESSITURAS}

Ao conversarmos recentemente com uma professora formadora de professores, chamounos atenção a preocupação por ela demonstrada quanto à importância e necessidade dos conhecimentos matemáticos, conhecimentos pedagógicos e conhecimentos tecnológicos estarem em sintonia em sua prática pedagógica. Segundo ela "o nosso não trabalhar esses três conhecimentos estará limitando os conhecimentos dos nossos alunos". Ao refletirmos sobre essa apreensão manifesta, lembramo-nos de Moran (2012 p. 13) quando compara a educação a um caleidoscópio. Diz ele: "Podemos enxergar diferentes realidades; podemos escolher mais de uma perspectiva de análise e cada uma terá sua lógica, seu fundamento, sua defesa, porque projetamos na educação nosso olhar parcial, nossas escolhas, nossa experiência”. 
Charlot (2000, p. 54) traz contribuição ímpar às colocações aqui expostas. Segundo ele, “A educação é uma produção de si por si mesmo, mas essa autoprodução só é possível pela mediação do outro e com sua ajuda. [...] uma educação é impossível se o sujeito a ser educado não investe pessoalmente no processo que o educa". Ainda segundo o autor, o sujeito nasce inacabado e deve construir-se. Essa construção deve partir de "dentro", visto que a educação é produção de si próprio. Para construir-se, o sujeito deve ir apropriando-se de uma humanidade que lhe é "exterior", logo essa produção reivindica a mediação do outro. "A educação não é subjetivação de um ser que não seria sujeito; o sujeito está sempre aí. A educação não é socialização de um ser que não fosse já social: o mundo, e com ele a sociedade, já está sempre presente.” (CHARLOT, 2000, p. 54).

As palavras apreensivas da professora formadora, o olhar de Moran (2012) para a educação e as colocações de Charlot (2000) nos instigaram a refletir sobre a formação dos professores formadores no processo de constituição profissional. Nessa reflexão consideramos como potencial a realização de atividades virtuais no desenvolvimento do processo formativo presencial, de modo que o presencial se virtualize e a distância se presencialize, o que, em resumo, significa a integração das TDIC na prática pedagógica. Conjecturamos, pois, sobre a essencialidade do uso dessas tecnologias e de ambientes virtuais [de aprendizagem] na formação dos professores formadores, possibilitando, inclusive, o extrapolar de fronteiras clássicas dos processos formativos.

O trabalho de Guérios (2002) vai ao encontro do apresentado. Em sua tese, a autora voltou o olhar para a formação de professores e investigou o movimento de constituição profissional de professores sob a ótica da complexidade, conforme Edgar Morin, com o intuito de "compreendê-los em sua totalidade interpretando seus saberes, suas ações e os sentidos que cada um atribuía ao que fazia, segundo as marcas da singularidade de cada um na sua relação com o mundo, com o conhecimento e consigo mesmo." (GUÉRIOS, 2002, p. 207). Nesse movimento, a autora buscou compreender nuances existentes entre a teoria e a prática que são constitutivas da prática didática dos professores. Ao retomar seu trabalho após alguns anos de vivência e experiência, Guérios (2019) menciona que identificou:

[...] que em uma perspectiva de complexidade tais nuances ${ }^{5}$ estão na autonomia do fazer docente, cuja criatividade se dá quando aceitam a imprevisibilidade característica do espaço educativo e estão abertos para o novo, o que demanda

\footnotetext{
5 “[...] nuances do mistério que há entre a teoria, a prática e... cada um, na composição do vir a ser professor." (GUÉRIOS, 2002, p. 207). 
estratégias didáticas compatíveis com o que se lhes apresenta. (GUÉRIOS, 2019, p. 223-224).

Ao concentrar esforços na formação de professores (inicial ou continuada), encontraremos pesquisas em diferentes modalidades de educação, dentre as quais citamos exemplos com o seguinte foco: formação de professores que ensinam Matemática (GUÉRIOS, 2002; NACARATO e PAIVA, 2008; OLIVEIRA e SCHERER, 2012; FIGUEIREDO e GROENWALD, 2019; EÇA, PEIXOTO e MADRUGA, 2021), formação de professores e educação presencial (SAUSEN, 2011; COSTA e MENDONÇA, 2014), na formação de professores e educação a distância (BAIRRAL, 2007; SÁ, 2007) e na formação de professores e educação semipresencial, também denominada bimodal (SCHERER, 2005; KUMMER, 2006).

Ao mencionarmos diferentes modalidades de educação, sincronicamente, remetemonos à premência do uso das tecnologias. Na atualidade o uso das TDIC, especificamente o uso de dispositivos tecnológicos (computador, notebook, tablet, celular) conectados à internet, sobretudo por viabilizar o uso de ambientes virtuais, é algo que defendemos (SAUSEN, 2011) e que, devido à pandemia de Covid-19, tornou-se recurso indispensável para a realização do processo de ensino e de aprendizagem de alunos de todas as modalidades de ensino. O mesmo pode ser dito em relação aos cursos de formação ofertados aos professores e aos professores formadores.

Soek e Haracemiv (2017) debruçaram-se sobre a modalidade de Educação a Distância $(\mathrm{EaD})$ e mencionam que à luz do pensamento complexo, em conformidade ao exposto por Morin, “[...] pode-se compreender ou caracterizar os princípios da $\mathrm{EaD}$ como um 'todo ${ }^{6}$ capaz de contemplar as diversas inter-relações do processo educativo mediado por tecnologias [...]" (SOEK e HARACEMIV, 2017, p. 257). Acreditamos que o mesmo pode ser proferido em relação às modalidades presencial e semipresencial de educação.

Atualmente são indiscutíveis as potencialidades do uso de tecnologias para o processo de ensino e de aprendizagem (CAMAS et al, 2013; BRITO et al, 2017). Na verdade, no ano de 2002, Morin já abordava sobre esta potencialidade ao afirmar que:

\footnotetext{
${ }^{6}$ Para Morin (2014) a soma das partes é mais que o todo, “[...] o todo organizado é alguma coisa a mais do que a soma das partes, porque faz surgir qualidades que não existiram nessa organização; essas qualidades são "emergentes", ou seja, podem ser constatadas empiricamente, sem ser dedutíveis logicamente; essas qualidades emergentes retroagem ao nível das partes e podem estimulá-las a exprimir suas potencialidades." (MORIN, 2014, p. 180).
} 
[...] é evidente que o desenvolvimento da mundialização cultural é inseparável do desenvolvimento mundial das redes midiáticas, da difusão mundial dos modos de reprodução (cassetes, cds, vídeos) e que a internet e a multimídia acelerarão e amplificarão todos os processos, diversos, concorrentes e antagônicos (ou seja, complexos) que evocamos (MORIN, 2002, p. 02).

Nesse cenário, afirmamos a necessidade de integração e não apenas a inserção das tecnologias à prática pedagógica e ao processo de ensino e de aprendizagem. Essa afirmativa é feita por compactuarmos com a ideia de Bittar (2010) quando a autora diz que o termo "inserção da tecnologia na educação" é aplicado para referenciar-se ao uso mais comum que tem sido feito da mesma. Para a autora “[...] o professor faz uso do giz quando sente a necessidade e o mesmo deve acontecer com a informática [e com outras tecnologias]" (BITTAR, 2010, p. 595). A partir disso, podemos considerar que a integração das tecnologias à prática pedagógica do professor acontece no momento em que este está trabalhando determinado conteúdo e faz uso dos recursos que considera úteis ao processo de aprendizagem de seus alunos.

Sobre o uso de ambientes virtuais, muitos são os estudos realizados que utilizaram esses espaços virtuais e suas ferramentas. Dentre eles, podemos destacar Scherer (2005), Kummer (2006), Bairral (2007), Sausen (2011), que buscaram analisar elementos do conhecimento docente (re)construídos através das interações realizadas nesses recursos. Scherer (2005) menciona que os ambientes virtuais representam um lócus para a constituição de comunidades virtuais de aprendizagem. Devido à sua estética e recursos tecnológicos disponíveis, as comunidades virtuais podem contribuir para a formação de sujeitos mais colaborativos e cooperativos, visto que em um AVA dificilmente há a pretensão de se estar sozinho.

Ainda, segundo a autora, esse é um espaço favorável à vida em comunidade, ao processo de comunicação de muitos para muitos, sem isolamentos, sem fronteiras, caracterizando um espaço democrático, onde todos podem participar igualmente das discussões, das produções, das tarefas propostas. Isso não o caracteriza como um espaço em que as opiniões e ideias de uns se sobrepõe as de outros, “[...] longe de fundir as inteligências individuais em uma espécie de magna indistinto, a inteligência coletiva é um processo de crescimento de diferenciação e de retomada recíproca das singularidades". (LÉVY, 1999, p. 32)

As palavras de Lévy (1999) vão ao encontro do exposto por Primo (2008), quando o autor trata de interação mútua. Entendemos por interação a "ação entre" os participantes da atividade, "inter+ação". O termo "mútua" refere-se às modificações recíprocas dos participantes durante a atividade, sendo possível afirmar que "ao interagirem, um modifica o outro.” (PRIMO, 2008, p. 57). No entanto, nenhum se sobrepõe ao outro ou o anula. Na medida 
em que as interações acontecem, experiências são trocadas, conhecimentos são construídos e solidificados.

Mas de que experiência se está falando? Ao mencionar "experiência", remetemo-nos à Larrosa (2011) e Guérios (2002). De Larrosa compreendemos que a experiência pode ser autêntica ou não. Autêntica é a que provoca transformação, é a que promove um movimento interior conforme sua afirmação de que "a experiência é 'isso que me passa'. Não isso que passa, senão "isso que me passa" 7 (2011, p. 05). Para Guérios (2002, p. 70), a experiência é "[ [...] mais do que aquilo que nos passa, a experiência é o que nos transpassa e que, por nos transpassar, nos marca, ecoa e ressoa continuamente dentro de nós, explica e fundamenta o vivido e o viver simultaneamente, provocando modificação".

Todavia para vivenciar essa experiência (GUÉRIOS, 2002; LARROSA, 2011), temos a convicção de que se faz necessário que nos mobilizemos:

O conceito de mobilização implica a ideia de movimento. Mobilizar é pôr em movimento; mobilizar-se é pôr-se em movimento. Para insistir nessa dinâmica interna é que utilizamos o termo de "mobilização", de preferência ao de "motivação". A mobilização implica mobilizar-se ("de dentro"), enquanto que a motivação enfatiza o fato de que se é motivado por alguém ou por algo (“de fora"). É verdade que, no fim da análise esses conceitos convergem: poder-se-ia dizer que eu me mobilizo para alcançar um objetivo que me motiva e que sou motivado por algo que pode mobilizarme. Mas o termo mobilização tem a vantagem de insistir sobre a dinâmica do movimento. (CHARLOT, 2000, p. 54-55).

Para Charlot (2000), o sujeito mobiliza-se em uma atividade quando investe nele próprio, quando faz uso de si mesmo como de um recurso, quando é posto em movimento por móbeis que o conduzem a um desejo, um sentido, um valor. A atividade possui então uma dinâmica interna que supõe uma troca com o mundo.

Segundo Charlot (2013), aprender exige uma atividade intelectual e só se empenha em uma atividade àquele que lhe confere um sentido. No momento em que esse sentido se distancia

\footnotetext{
${ }^{7}$ No texto "Experiência e alteridade em educação", o autor explica e exemplifica o significado da expressão "isso que me passa" a partir de um exemplo com foco em alfabetização. Diz Larrosa (2011), "[...] alfabetização que não tem a ver com ensinar a ler no sentido da compreensão, senão no sentido da experiência. Uma alfabetização que tenha a ver com formar leitores abertos à experiência, a que algo lhes passe ao ler, abertos, portanto, a não se reconhecer no espelho". Ainda, experiência como "isso que me passa" tem três significados: “- Primeiro, que a experiência é uma relação com algo que não sou. Neste caso, o livro de Kafka: sua condição de alteridade, de exterioridade, de amenidade. - Segundo, que a experiência é uma relação em que algo tem lugar em mim. Neste caso, que minha relação com o texto, digo, minha leitura, é de condição reflexiva, volta para dentro, subjetiva, que me implica no que sou, que tem uma dimensão transformadora, que me faz outro do que sou. Por isso, depois da leitura, eu já não sou o mesmo de antes, já não posso olhar-me impávido no espelho. - E terceiro, que a experiência é uma relação em que algo passa de mim a outro e do outro a mim. E nesse passa, tanto eu como o outro, sofremos alguns efeitos, somos afetados." (LARROSA, 2011, p. 10). 
do resultado pretendido pela ação de estudar, o engajamento nesta ação torna-se frágil. Contrariamente, quando o motivo e o objetivo da atividade convergem, esta faz muito sentido e experimenta-se prazer ao desenvolvê-la. Este prazer pode ser ainda mais potencializado ao se atingir o objetivo proposto. Assim, compactuando com o autor, "atividade, sentido, prazer" (CHARLOT, 2013, p. 146) são os termos da equação pedagógica a ser resolvida.

Mediante o exposto e tendo como pano de fundo a questão da equação pedagógica referenciada, interessou-nos investigar sobre a integração das TDIC e de ambientes virtuais [de aprendizagem] em cursos presenciais de formação dos professores formadores. A seguir apresentamos o caminho trilhado em relação à pesquisa bibliográfica que realizamos com o objetivo de descortinar que tendências, convergências e complementaridades apresentam as pesquisas stricto sensu nos programas brasileiros de pós-graduação tendo como pano de fundo as TDIC e os ambientes virtuais [de aprendizagem].

\section{O CAMINHO TRILHADO E APONTAMENTOS}

Para a obtenção de um panorama da produção científica stricto sensu nos programas brasileiros de pós graduação, realizamos no Catálogo de teses e dissertações da CAPES e na BDTD a seleção dos trabalhos que apresentavam foco de análise no uso de TDIC e de ambientes virtuais [de aprendizagem] no ensino presencial e que trouxessem o entrelaçamento das Licenciaturas em Matemática e em Pedagogia, ou ainda, que esse entrelaçamento se estendesse ao Curso Formação de Docentes (antigo Magistério) no nível de Ensino Médio e no tratamento da formação dos professores que formam professores e ensinam Matemática, perfazendo o período de 2000 a 2019. Para isso, utilizamo-nos dos buscadores: "professor formador de professor", "ambiente virtual", "ensino presencial", "licenciatura matemática", "licenciatura pedagogia", "ensino médio" e "educação básica", que nos trouxe um total de 30.890 (trinta mil oitocentos e noventa).

Ao analisar os resultados, encontramos trabalhos datados em período anterior à Plataforma Sucupira, cujos focos estavam no uso de recursos tecnológicos em disciplinas na Educação Básica. Nenhum deles, portanto, contemplava o foco de investigação almejado.

Prosseguindo as buscas, aplicamos filtros disponíveis nesses Bancos e adjacentes à nossa pesquisa, resultando em 1783 (mil setecentos e oitenta e três) trabalhos. Para a classificação de todos esses trabalhos encontrados, primeiramente realizamos leitura e análise 
cuidadosa dos títulos, resumos, palavras-chave e sumário. Do total encontrado, foram eliminados 1642 (mil seiscentos e quarenta e dois), ou seja, dessa leitura 141 (cento e quarenta e um) trabalhos foram selecionados. Desses, 66 (sessenta e seis) foram eliminados a partir do resumo, 5 (cinco) não foram encontrados os arquivos para leitura e 70 (setenta) foram selecionados para análise mais detalhada, devido ao fato de irem ao encontro, de alguma forma, da pesquisa pretendida. Isto posto, optamos pela realização de uma segunda análise dos 70 trabalhos selecionados, utilizando como critérios de seleção, as pesquisas cujo foco tivesse o direcionamento à formação de professores formadores que ensinam matemática e o uso de tecnologias e/ou de ambientes virtuais [de aprendizagem] no ensino presencial.

Nessa segunda análise, foram selecionados 13 (treze) trabalhos. Dos selecionados: 4 (quatro) abordam a Formação de Professores e Ambientes Virtuais (AV); 4 (quatro) possuem foco na Formação de Professores; 1 (um) tem enfoque em Ambientes Virtuais de Aprendizagem (AVA); 1 (um) destaca o Conhecimento Tecnológico e Pedagógico do Conteúdo (CTPC) e a Formação de Professores; e, 3 (três) dão destaque à Formação de Professores e Tecnologias de Informação e Comunicação (TIC).

Curiosamente, não encontramos nenhuma tese entre os 30.890 trabalhos, o que nos levou a conjecturar sobre a inexistência de estudos longitudinais. Decidimos pela exclusão de descritores devido a suspeita de que a união deles provocava a exclusão de trabalhos. Ao concluirmos essa busca, apenas um trabalho caracterizou estudo longitudinal.

Iniciamos o processo de exclusão pelo descritor "ensino médio", mas novamente não encontramos nenhuma tese. A seguir eliminamos o descritor "educação básica", resultando em 3176 (três mil cento e setenta e seis) trabalhos. Desse total 594 (quinhentas e noventa e quatro) teses. Procedemos, então, a análise das 594 teses resultantes da busca a partir dos descritores: "professor formador de professor", "ambiente virtual", "ensino presencial", "licenciatura matemática" e "licenciatura pedagogia".

Realizamos a leitura cuidadosa dos títulos, dos resumos, das palavras-chave e sumários das 594 teses. Em uma primeira seleção, 59 (cinquenta e nove) foram elencadas para mais análises, sendo que 4 (quatro) teses não foram encontradas, totalizando 55 (cinquenta e cinco). Os trabalhos analisados anteriores a 2010 trazem enfoque diferente do que temos atualmente e, na sua maioria, as TIC utilizadas estão em desuso atualmente.

Dando continuidade às nossas análises, sistematicamente, lemos novamente o resumo, o sumário e realizamos leitura flutuante do corpo de cada uma das 55 teses, resultando em uma 
seleção de 11 (onze) trabalhos. Desses, 3 (três) abordam a Formação de Professores e Ambientes Virtuais; 6 (seis) destacam a Formação de Professores, o pensamento complexo / complexidade, e 2 (duas) destacam o CTPC e a Formação de Professores.

Como resultado final dessa busca, totalizamos 24 (vinte e quatro) trabalhos selecionados, sendo 13 dissertações e 11 teses que classificamos em 6 (seis) temáticas: $1^{\text {a }}$ ) 7 (sete) abordam a Formação de Professores e Ambientes Virtuais; 2 $2^{\mathrm{a}} 6$ (seis) destacam a Formação de Professores e o pensamento complexo / complexidade; $3^{\mathrm{a}}$ ) 3 (três) destacam o CTPC e a Formação de Professores; $4^{\mathrm{a}}$ ) 4 (quatro) possuem foco na Formação de Professores; $\left.5^{\mathrm{a}}\right) 1$ (um) tem enfoque em Ambientes Virtuais de aprendizagem; $6^{\mathrm{a}}$ ) 3 (três) dão destaque à Formação de Professores e TIC, conforme quadro a seguir (QUADRO 1).

\begin{tabular}{|c|c|c|c|}
\hline Temática & Dissertação & Tese & Total \\
\hline Formação de Professores e Ambientes Virtuais & 4 & 3 & 7 \\
\hline $\begin{array}{c}\text { Formação de Professores e o pensamento complexo / } \\
\text { complexidade }\end{array}$ & 0 & 6 & 6 \\
\hline $\begin{array}{c}\text { Conhecimento Tecnológico e Pedagógico do Conteúdo } \\
\text { (CTPC) e a Formação de Professores }\end{array}$ & 1 & 2 & 3 \\
\hline Formação de Professores & 4 & 0 & 4 \\
\hline Ambientes Virtuais de aprendizagem & 1 & 0 & 3 \\
\hline $\begin{array}{c}\text { Formação de Professores e Tecnologias de Informação e } \\
\text { Comunicação (TIC) }\end{array}$ & 3 & 0 & $\mathbf{2 4}$ \\
\hline Total & $\mathbf{1 3}$ & $\mathbf{1 1}$ & $\mathbf{2 0 1 9}$ \\
\hline
\end{tabular}

Quadro 1 - Temáticas investigativas no catálogo de teses e dissertações da CAPES e na BDTD (setembro/2019). Fonte: Produção de Sausen e Guérios (2020).

Essa classificação por temática foi um processo longo, dado que alguns dos trabalhos selecionados demonstravam características que induziam a classificá-los em mais de uma temática pelas similitudes apresentadas. Realizamos, então, inúmeras leituras de cada um dos 24 (vinte e quatro) trabalhos selecionados, incluindo cada um deles em uma única temática.

Dos 24 trabalhos selecionados, foi possível observarmos que: 21 (vinte e um) apresentaram o locus de desenvolvimento da pesquisa no mesmo estado de origem da Universidade à qual o pesquisador está vinculado: 3 (três) São Paulo/São Paulo; 7 (sete) Rio Grande do Sul/Rio Grande do Sul, sendo que, um deles o locus de desenvolvimento da pesquisa foi um curso de extensão, ofertado na modalidade de Educação a Distância (EaD), tendo a participação estendida a toda região sul; 2 (dois) Santa Catarina/Santa Catarina; 2 (dois) Mato Grosso/Mato Grosso; 3 (três) Minas Gerais/Minas Gerais; 1 (um) Paraná/Paraná; 1 (um) Bahia/Bahia; 1 (um) Rondônia/Rondônia; e, 1 (um) Pará/Pará. Apenas 2 (dois) apresentaram o locus de desenvolvimento da pesquisa em estado diferente da Universidade à qual o pesquisador está vinculado: 1 (um) Rio de Janeiro/São Paulo; 1 (um) Rio Grande do Sul/Minas Gerais, e 1 
(um) apresentou o locus de desenvolvimento no mesmo estado de origem da Universidade à qual o pesquisador está vinculado e um segundo locus em estado diferente. Isso nos leva a conjecturar que, cada vez mais, alunos de mestrado e de doutorado vêm buscando informações/ensino necessários à produção de conhecimento por meio de pesquisas, aplicando a ciência em prol da sociedade e, principalmente, da comunidade a que pertencem.

Dando sequência à pesquisa bibliográfica, realizamos mais perquirições no banco da CAPES e na BDTD, agora por meio de todas as combinações possíveis entre os buscadores já elencados: "professor formador de professor", "ambiente virtual", "ensino presencial", "licenciatura matemática", "licenciatura pedagogia", "ensino médio" e "educação básica" e o uso do operador booleano AND, resultando em 34 (trinta e quatro) combinações. Dessas, 27 (vinte e sete) resultaram em zero trabalhos encontrados e, apenas 7 (sete), geraram resultados diferente de zero: 1. "magistério" AND "ambiente virtual" AND "professor formador" - 2 (dois) resultados; 2. "licenciatura pedagogia" AND "formação de docentes" - 1 (um) resultado; 3. "ambiente virtual" AND "magistério" AND "matemática" - 3 (três) resultados; 4. "ambiente virtual" AND "magistério" - 15 (quinze) resultados; 5. "ambiente virtual" AND "ensino médio" AND "matemática" - 132 (cento e trinta e dois) resultados; 6. "ambiente virtual" AND "educação básica" AND "matemática" 81 (oitenta e um) resultados; 7. "educação básica" AND "ambiente virtual" AND "formação de professores" 71 (setenta e um) resultados.

Em síntese, a perquirição por meio de combinações entre os buscadores elencados e o uso do operador booleano AND trouxe 305 (trezentos e cinco) resultados, sendo que para a análise desses trabalhos, seguimos o mesmo processo: leitura do título, resumo e palavraschave. Do montante de trabalhos catalogados, 270 (duzentos e setenta) foram excluídos, 2 (dois) não foram encontrados, 30 (trinta) estão repetidos e 4 (quatro) trabalhos foram incluídos: três dissertações e uma tese (QUADRO 02).

\begin{tabular}{|l|c|c|c|c|c|}
\hline \multicolumn{1}{|c|}{ Busca (String) } & Encontrado & $\begin{array}{c}\text { Não } \\
\text { Encontrado }\end{array}$ & Excluído & Repetido & $\begin{array}{c}\text { Incluídos } \\
\text { no corpus }\end{array}$ \\
\hline $\begin{array}{l}\text { "magistério" AND "ambiente virtual" } \\
\text { AND "professor formador" }\end{array}$ & 2 & 0 & 0 & 2 & 0 \\
\hline $\begin{array}{l}\text { "licenciatura pedagogia" AND "formação } \\
\text { de docentes" }\end{array}$ & 1 & 0 & 1 & 0 & 0 \\
\hline $\begin{array}{l}\text { "ambiente virtual" AND "magistério" } \\
\text { AND "matemática" }\end{array}$ & 3 & 0 & 2 & 1 & 0 \\
\hline "ambiente virtual" AND "magistério" & 15 & 1 & 12 & 2 & 0 \\
\hline $\begin{array}{l}\text { "ambiente virtual" AND "ensino médio" } \\
\text { AND "matemática" }\end{array}$ & 132 & 0 & 124 & 6 & 2 \\
\hline $\begin{array}{l}\text { "ambiente virtual" AND "educação básica" } \\
\text { AND "matemática" }\end{array}$ & 81 & 1 & 76 & 4 & 1 \\
\hline
\end{tabular}




\begin{tabular}{|c|c|c|c|c|c|}
\hline $\begin{array}{l}\text { "educação básica" AND "ambiente virtual" } \\
\text { AND "formação de professores" }\end{array}$ & 71 & 0 & 55 & 15 & 1 \\
\hline Total & 305 & 2 & 270 & 30 & 4 \\
\hline
\end{tabular}

Quadro 2 - Busca utilizando combinações e operador booleano AND no catálogo de teses e dissertações da CAPES e na BDTD (setembro de 2019).

Fonte: Produção de Sausen e Guérios (2020).

Com a realização da pesquisa bibliográfica findada para esse momento, encontramos trabalhos realizados com o uso de ambientes virtuais no Ensino Presencial (SASSI, 2016; SALES, 2017; ANDRADE, 2018), hospedados em plataformas, muitos deles na plataforma Moodle sob as perspectivas de pesquisa quantitativa e qualitativa. Outro ponto importante a ser mencionado, é que grande porcentagem dos estudos consultados aponta que o uso que se fez destes espaços caracterizou apenas Ambiente Virtual com características de depositário de materiais e uma minoria como Ambiente Virtual de Aprendizagem, como espaço onde as interações e aprendizagens acontecem.

Foram encontrados muitos trabalhos com foco na Educação a Distância, na Educação Bimodal (Educação Híbrida: Ensino Presencial + Educação a Distância), no ensino presencial em cursos de Engenharia, disciplinas de Cálculo Diferencial e Integral, entre outros. Ressaltamos que não encontramos estudos que evidenciem o uso das ferramentas de ambientes virtuais no Ensino Presencial e realizem o entrelaçamento entre as Licenciaturas em Matemática e em Pedagogia. Também não encontramos esse entrelaçamento com o curso Formação de Docentes (Ensino Médio) e o olhar voltado aos formadores de professores com foco nos conhecimentos tecnológicos, pedagógicos e de conteúdos (nessa pesquisa, conhecimentos matemáticos).

\section{A FORMAÇÃO DE FORMADORES DE PROFESSORES QUE ENSINAM MATEMÁTICA: TENDÊNCIA, CONVERGÊNCIA E COMPLEMENTARIDADE}

Com base na tessitura apresentada até o momento é chegada a hora de tecermos análises sobre os achados. Assim, nesse cenário, retomamos a questão central apresentada com o intuito de descortinar que tendência, convergência e complementaridade apresentam as pesquisas stricto sensu nos programas brasileiros de pós graduação tendo como pano de fundo as TDIC e os ambientes virtuais [de aprendizagem]. 
A pesquisa bibliográfica evidenciou a convergência de que a formação de professores deve ser uma preocupação constante de todos os envolvidos no e com o processo educacional e isso se estende aos professores formadores de professores.

Emergiram dos estudos selecionados a importância e a necessidade de que o professor tenha tempo (NAZÁRIO, 2015; AZEREDO, 2016) para investir em suas aulas, em sua formação e para que ele possa vir a se apropriar dos conhecimentos pedagógicos, de conteúdo e tecnológicos. Importante mencionarmos que o tempo que os estudos se referiram foi o tempo cronológico, aquele ditado pelo relógio e calendário.

Nessa direção, Gonçalves (2014) menciona que para que cheguemos ao desejado conhecimento do conteúdo pedagógico e tecnológico, conforme proposto no modelo Technological Pedagogical Content Knowledge (TPACK), necessitamos de tempo, suporte e experimentações sucessivas, pois a articulação entre conteúdo específico e TDIC não é algo trivial, mas sim um processo. Da mesma forma, faz-se necessário que o professor, seja ele professor formador de professores ou não, esteja em constante formação para que desenvolva o CTPC (CASTRO, 2014; NAKASHIMA, 2014; ROCHA, 2015; NISHIO, 2017).

A partir dos estudos mencionados, temos um indício de complementaridade, sendo possível inferir que se faz necessária a disponibilidade desses quatro itens: tempo, suporte técnico, experimentações sucessivas e formação continuada para que os professores consigam articular as TDIC que estejam disponíveis em seu contexto escolar com o conteúdo específico que lecionam, potencializando os processos de ensino e de aprendizagem, por meio de formações e trocas de experiências com seus pares.

Ainda, em relação ao tempo entrelaçado ao uso de ambiente virtual (AV), a falta desse elemento importantíssimo implica no uso de poucas ferramentas ou na repetição constante das mesmas ferramentas disponíveis nesses espaços virtuais. Isso porque para utilizar uma maior quantidade e variedade de ferramentas disponíveis nesses espaços, é necessário que o professor formador tenha tempo para explorar suas funcionalidades (MIRANDA, 2015), potencialidades e adequabilidades ao que se almeja para cada aula.

Nesse sentido, as pesquisas apontam que as ferramentas disponíveis em espaços virtuais mais utilizadas pelos professores tendem a ser as assíncronas (comunicação a qualquer tempo, na qual emissor e receptor não precisam estar no mesmo tempo significativo), ou seja, os fóruns de discussão, tarefa e questionário (AZEREDO, 2016; NISHIO, 2017). Não havendo apontamento às síncronas (que permitem a comunicação em espaços diferentes e ao mesmo 
tempo) - chat, por exemplo. Também são mencionados o uso de softwares de geometria dinâmica e construtores de gráficos de funções (NISHIO, 2017).

As pesquisas também apontam o uso de ambientes virtuais, principalmente na modalidade de Educação a Distância (SANTOS, 2005; GONÇALVES, 2014; NAZÁRIO, 2015; MIRANDA, 2015; BRUN MENEGOTTO, 2015). Isso se justifica por representar recurso indispensável para essa modalidade de ensino. Houve também o apontamento do uso de AV não institucional (Facebook) ao invés do uso de AV institucional (Moodle), trazendo à luz das discussões a semipresencialidade - 20\% da carga horária EaD (BENTO, 2016), sob a perspectiva de o uso de AV não institucional apresentar facilidades para seu uso em detrimento aos ambientes virtuais institucionais, uma delas é exigir menor velocidade de internet para, por exemplo, baixar vídeos. Podemos acrescentar, também, menor burocracia para acesso aos espaços virtuais não institucionais.

Em relação ao Ensino Presencial, o uso se deu em disciplinas que compõem a grade curricular de cursos de pós-graduação e o olhar esteve voltado aos professores e ao uso que esses fazem dos espaços virtuais e de suas ferramentas (NAKASHIMA, 2014; NISHIO, 2017). De igual modo, foram analisados cursos com subárea Informática - área Ciências Exatas e Administração - área Ciências sociais aplicadas (AZEREDO, 2016), apontando que o uso que foi feito desses espaços virtuais e suas ferramentas tinham a intenção de alcançar os objetivos propostos ao ensinar algum conteúdo.

Em curso de licenciatura e bacharelado, Sales (2017) investigou se o uso dos ambientes virtuais contribui para o processo de ensino e aprendizagem dos cursos presenciais, e quais os principais fatores que interferem, limitam ou facilitam o uso do AV Moodle no ensino presencial. Os resultados que a pesquisa trouxe demonstraram que os docentes participantes do estudo ainda não implementaram em suas aulas o uso do AV Moodle, mas apresentam uma postura favorável à continuidade do processo de formação para o uso da plataforma ao considerar que o curso de capacitação (meio para produção de dados) deu subsídios básicos e iniciais sobre essa tecnologia. Todavia, Sales (2017) aponta a necessidade de melhoria da infraestrutura de rede (internet) e avanço nos processos de capacitação em práticas pedagógicas no AV.

Ademais, os ambientes virtuais foram utilizados no Ensino Presencial com foco na Educação Básica, que culminou na proposição de curso voltado aos professores desse nível de escolaridade, focando no modelo de sala de aula invertida, enquanto curso de capacitação 
continuada estruturado a partir dos pressupostos do hibridismo (ANDRADE, 2018). Ainda, como curso em AV hospedado na Plataforma Moodle com característica de atividade complementar à disciplina de Matemática sob a ótica do Design Instrucional (SASSI, 2016).

Dos estudos selecionados, há a tendência para o fato de que os professores utilizam as TDIC cotidianamente em suas atividades pessoais e para preparar suas aulas, mas em menor escala, nos espaços profissionais ou em sala de aula. Nesse viés, Martini (2013) menciona que mediante a formação que tiveram, os professores ofertam aos seus alunos apenas rudimentos de informática e oportunidade de vivenciar algumas experiências de aprendizagem em que as TDIC eram utilizadas como meros recursos para reanimar velhas práticas de ensino, sem modificar as formas de ensinar e de aprender.

Similarmente, Castro (2014) aponta que o Projeto Político Pedagógico (PPP) de determinada instituição de Ensino Superior contempla a temática tecnologia, desenvolvendo um componente curricular. No entanto, na ementa do componente curricular Tecnologias na Educação faltam conteúdos que tratam especificamente da temática para Educação Básica. Segundo relatos dos participantes da pesquisa, essa disciplina foi ministrada por um professor, com prioridade para a teoria.

\section{ALGUMAS CONSIDERAÇÕES}

Com fundamento no apresentado, podemos inferir que as pesquisas stricto sensu nos programas brasileiros de pós-graduação, tendo com pano de fundo as TDIC e os ambientes virtuais, revelaram a existência de tendência, convergência e complementaridade.

A tendência despontou ao revelar o fato de que os professores utilizam frequentemente as TDIC em seus afazeres pessoais, mas em menor escala, em suas atividades profissionais em sala de aula. Ainda, ficou evidenciado que os professores oportunizam aos seus alunos experiências de aprendizagem conforme as vivenciadas por eles em seus processos de formação (inicial ou continuada). Importante salientar que isso é feito no intuito de proporcionar acurado processo de ensino e de aprendizagem a seus alunos. Circunstância que nos conduz à convergência de que a formação de professores carece de constante atenção por parte de todos os envolvidos no e com o processo educacional. Para tal, devemos considerar os indícios de complementaridade encontrados, ou seja, é fundamental que o professor tenha disponível tempo (cronológico), suporte técnico, realize experimentações sucessivas e reflita sobre elas. Tudo 
isso entrelaçado a formação continuada, que lhes oportunize articular as TDIC que estejam disponíveis em seu contexto escolar com o conteúdo específico que lecionam.

Em relação ao exposto, ponderamos que o uso de ambientes virtuais, se utilizados com o viés de ambientes virtuais de aprendizagem (SAUSEN, 2011), em processos de formação continuada de professores, viabiliza o extrapolar das fronteiras presencial-virtual / virtualpresencial, promovendo uma simbiose entre espaço presencial e espaço virtual. Fato que possibilita condições para a ocorrência de interações e trocas de experiências com seus pares, potencializando os processos de ensino e de aprendizagem. Assim, na medida em que as interações acontecem, as experiências são trocadas e os conhecimentos são construídos e solidificados.

Diante disso, compactuamos com as palavras de Charlot (2013), quando diz que “atividade, sentido e prazer" são os termos da equação pedagógica. Acrescentamos a isso o desenvolvimento de uma cultura de formação, sendo que a interlocução entre as diferentes esferas de ensino ${ }^{8}$ pode ser um dos caminhos a ser trilhado.

\section{REFERÊNCIAS}

ALMEIDA, Maria Elizabeth Bianconcini de. Educação a Distância na Internet: abordagens e contribuições dos ambientes digitais de aprendizagem. Educação e Pesquisa [online], v.29, n.2, p. 327-340, ISSN 1678-4634. https://doi.org/10.1590/S1517-97022003000200010.

ANDRADE, M. Q. de. Diálogos em Prática: proposta de formação para o uso do ambiente virtual de aprendizagem (AVA) na perspectiva dos professores. 2018. 136f. Dissertação (Mestrado) - Universidade Federal do Paraná, Setor de Educação, Programa de PósGraduação em Educação, Curitiba, 2018. Disponível em: https://acervodigital.ufpr.br/handle/1884/57180 . Acesso em: 29 nov. 2020.

\section{AZEREDO, I. C. da S. Recursos do MOODLE como apoio à Prática Pedagógica:}

Investigando o Fazer Docente. 2016. 135f. Dissertação (Mestrado) - Pontifícia Universidade Católica do Rio Grande do Sul, Escola de Humanidades, Programa de Pós-Graduação em Educação, Porto Alegre, 2016. Disponível em: http://tede2.pucrs.br/tede2/handle/tede/7137 . Acesso em: 29 nov. 2020.

BAIRRAL, Marcelo Almeida. Discurso, interação e aprendizagem matemática em ambientes virtuais a distância. Seropédica, RJ: Editora Universidade Rural, 2007.

BENTO, M. C. M. Ambientes Virtuais de Aprendizagem Institucionais e não

Institucionais: estudo de caso com professores de uma instituição de ensino superior

\footnotetext{
${ }^{8}$ Municipal: Educação Infantil e Anos Iniciais (Ensino Fundamental I); Estadual: Ensino Fundamental II, Ensino Médio e Cursos Profissionalizantes; e, Federal: cursos profissionalizantes e Ensino Superior. 


\section{REAMEC \\ REVISTA DA REDEAMAZÔNICA DE EDUCAÇȦO \\ EM CIĖNCLASE MATEMATIC}

salesiana. 2016. 140f. Tese (Doutorado) - Pontifícia Universidade Católica de São Paulo, Programa de Estudos Pós-Graduados em Tecnologia da Inteligência e Design Digital, São Paulo, 2016. Disponível em: https://tede2.pucsp.br/handle/handle/18782. Acesso em: 26 jan. 2021.

BITTAR, M. Parceria Escola X Universidade na Inserção da Tecnologia nas Aulas de Matemática: um projeto de pesquisa-ação. In: CUNHA, A. M. de O. [et al.] (ORGs.).

Convergências e tensões no campo da formação e do trabalho docente. Belo Horizonte, MG: Autêntica, 2010. (Coleção Didática e Prática de Ensino). p. 591-609. Disponível em: http://endipe.fae.ufmg.br/livros/Livro 5.PDF . Acesso em: 26 jan. 2021.

BRITO, G. da S.; et al. Formação Continuada de Professores em Tecnologia: A - Ousadia na Dialogicidade entre a Universidade e a Escola. Revista e-Curriculum. v. 15, p. 221-248, 2017. https://doi.org/10.23925/1809-3876.2017v15i1p221-248

BRUN MENEGOTTO, D. Práticas Didáticas em Ambiente Virtual de Aprendizagem: modificações da ação docente. 2015. 138f. Tese (Doutorado) - Universidade Federal do Rio Grande do Sul, Faculdade de Educação, Programa de Pós-Graduação em Educação, Porto Alegre, 2015. Disponível em: https://lume.ufrgs.br/handle/10183/117573 . Acesso em: 28 jan. 2021.

CAMAS, N. P. V.; et al. Professor e Cultura Digital: reflexão teórica acerca dos novos desafios na ação formadora para nosso século. Reflexão e Ação (Online). v. 21, n.2, p.179198, 2013. Disponível em: https://online.unisc.br/seer/index.php/reflex/article/view/3834. Acesso em: 28 jan. 2021. http://dx.doi.org/10.17058/rea.v21i2.3834

CASTRO, A. N. de. Formação Inicial: a contribuição para o uso pedagógico das TIC na educação básica - um estudo no curso de pedagogia da UFMT/campus Cuiabá. 2014. 113f. Dissertação (Mestrado) - Fundação Universidade Federal de Rondônia, Programa de PósGraduação em Educação, Porto Velho, 2014. Disponível em: http://www.ppge.unir.br/uploads/62248421/arquivos/DISSERTA O ANDR IA NUNES DE CASTRO 1826375272.pdf. Acesso em: 28 jan. 2021.

CHARLOT, Bernard. Da relação com o saber às práticas educativas. 1. ed. São Paulo: Cortez, 2013.

CHARLOT, Bernard. Da relação com o saber: elementos para uma teoria. Porto Alegre: Artmed, 2000.

COSTA, P. de S.; MENDONÇA, L. de S. O uso da Plataforma Moodle como apoio ao Ensino Presencial. DiversaPrática - Revista Eletrônica da Divisão de Formação Docente. v. 2, n.1, p. 146-194 , jan/jun, 2014 - ISSN 2317-0751. Disponível em: http://www.seer.ufu.br/index.php/diversapratica/article/view/26430

EÇA, J. L. M.; PEIXOTO, J. L. B. \& MADRUGA, Z. E. F. (2021). Formação continuada à luz da Etnomodelagem: construção de uma proposta de ensino com professores que ensinam matemática no Ensino Fundamental. REAMEC-Rede Amazônica de Educação em Ciências e Matemática, 9(1), e21005. http://dx.doi.org/10.26571/reamec.v9i1.11384. 
FIGUEIREDO, F. F.; GROENWALD, C. L. Design de problemas matemáticos com o uso de Tecnologias Digitais sob o enfoque da formulação de problemas subsidiários. In: Revista de Educação, Ciência e Cultura. Canoas, v. 24, n. 1, p. 213-216, mar.2019.

http://dx.doi.org/10.18316/recc.v24i1.4235

FIORENTINI, Dario; LORENZATO, Sergio. Investigação em Educação Matemática:

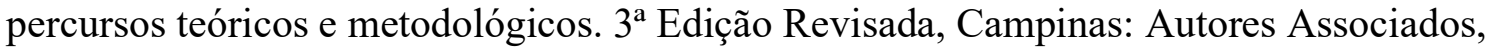
2006.

GONÇALVES, H. C. D. Formação continuada de professores para o uso do ambiente virtual de aprendizagem no curso de pedagogia: a experiência do PARFOR/UEPA. 2014. 150 f. Dissertação (Mestrado) - Universidade do Estado do Pará, Centro de Ciências Sociais e Educação, Programa de Pós-Graduação em Educação, Belém, 2014. Disponível em:

https://ccse.uepa.br/ppged/wpcontent/uploads/dissertacoes/08/heden_clazyo_dias_gonalves.pdf. Acesso em: 28 jan. 2021.

GUÉRIOS, E. Espaços oficiais e intersticiais da formação docente: história de um grupo de professores na área de ciências e Matemática. 2002. 234 f. Tese (Doutorado) - Universidade Estadual de Campinas, Faculdade de Educação, Programa de Pós-Graduação em Educação, Campinas, 2002. Disponível em: http://repositorio.unicamp.br/handle/REPOSIP/253667. Acesso em: 28 jan. 2021.

GUÉRIOS, E. Contribuições do pensamento complexo para a formação de professores em uma perspectiva transdisciplinar. In: SÁ, R. A. de; BEHRENS, M. A. (Orgs). Teoria da complexidade: contribuições epistemológicas e metodológicas para uma pedagogia complexa. Curitiba, PR: Appris, 2019.

KOLlER, S. H.; COUTO, M. C. de P. de P.; HOHENDORFF, J. von (Orgs.). Manual de produção científica. Porto Alegre, RS: Penso, 2014. Disponível em:

https://www.biosanas.com.br/uploads/outros/artigos_cientificos/18/6505082c2a7c23986651c 7b1f7a4a92e.pdf. Acesso em: 26 mar. 2021.

KUMMER, M. J. Aprendizagem Cooperativa - Uma abordagem em cursos bimodais de Especialização usando o Ambiente Virtual de Aprendizagem - Eureka. 2006. 158f.

Dissertação (Mestrado) - Pontifícia Universidade Católica, Programa de Pós-Graduação em Educação, Curitiba, 2006. Disponível em:

http://www.biblioteca.pucpr.br/tede/tde busca/arquivo.php?codArquivo=566. Acesso em: 28 jan. 2021.

LARROSA, J. Experiência e alteridade em educação. Revista Reflexão e Ação, Santa Cruz do Sul. v.19, n.2, p. 4-19, jul./dez. 2011. http://dx.doi.org/10.17058/rea.v19i2.2444

LÉVY, Pierre. A inteligência coletiva: por uma antropologia do ciberespaço. Tradução por Luiz Paulo Rouanet. 2 ed. São Paulo: Loyola, 1999. 212p.

MARTINI, C. M. A formação do professor de matemática e os desafios da inclusão das tecnologias de informação e comunicação na prática pedagógica. 2013. 118f. Dissertação 
(Mestrado) - Fundação Universidade Federal de Rondônia, Programa de Pós-Graduação em Educação, Porto Velho, 2013. Disponível em: http://ri.unir.br/jspui/hanle/123456789/1965. Acesso em: 28 jan. 2021.

MIRANDA, G. dos S. S. Tecnologia, Interação e Interatividade: desafios para o docente em ambientes virtuais de aprendizagem. 2015. 105f. Dissertação (Mestrado) - Universidade do Vale do Sapucaí, Programa de Pós-Graduação em Educação, Pouso Alegre, 2015.

Disponível em: http://www.univas.edu.br/me/docs/dissertacoes2/17.pdf . Acesso em: 28 jan. 2021.

MORAN, J. M. Pedagogia integradora do presencial-virtual. Set. 2002. Disponível em: http://www.abed.org.br/congresso2002/trabalhos/texto50.htm . Acesso em: 26 mar 2021.

MORAN, José Manoel. A educação que desejamos: Novos desafios e como chegar lá. 5. ed. Campinas, SP: Papirus, 2012.

MORAN, J. M. Propostas de mudança nos cursos presenciais com educação on-line. Set. 2004. Disponível em:

http://www.eca.usp.br/prof/moran/site/textos/educacao online/propostas.pdf . Acesso em: 26 mar 2021.

MORIN, Edgar. Abertura do Seminário Internacional de Educação e Cultura - SESC Vila Mariana, agosto/2002 - São Paulo. Disponível em:

http://acervo.plannetaeducacao.com.br/portal/artigo.asp?artigo=619. Acesso em: 26 mar. 2021.

MORIN, Edgar. Ciência com Consciência. Tradução de Maria D. Alexandre e Maria Alice Araripe de Sampaio Dora. 16.ed. Rio de Janeiro: Bertrand Brasil, 2014.

NACARATO, A. M.; PAIVA, M. A. V. A Formação do Professor que Ensina Matemática: estudos e perspectivas a partir das investigações realizadas pelos pesquisadores de GT 7 da SBEM. In: NACARATO, A. M.; PAIVA, M, A. V. (Orgs.). A Formação do Professor que Ensina Matemática: perspectivas e pesquisas. Belo Horizonte, MG: Autêntica, 2008.

NAKASHIMA, R. H. R. A dialética dos conhecimentos pedagógicos dos conteúdos tecnológicos e suas contribuições para a ação docente e para o processo de aprendizagem apoiados por ambiente virtual. 2014. 287f. Tese (Doutorado) - Faculdade de Educação da Universidade de São Paulo, Programa de Pós-Graduação em Educação, São Paulo, 2014. Disponível em: https://teses.usp.br/teses/disponiveis/48/48134/tde-01102014134609/pt-br.php. Acesso em: 28 jan. 2021.

NAZÁRIO, K. R. de P. Conhecimentos docentes para educação on-line : contribuições de um curso de formação em EaD da UFSCar. 2015. 95 f. Dissertação (Mestrado) Universidade Federal de São Carlos, Programa de Pós-Graduação em Educação, São Carlos, 2015. Disponível em: https://repositorio.ufscar.br/handle/ufscar/7074. Acesso em: 28 jan. 2021. 
NISHIO, A. L. Formação continuada de professores de matemática em um ambiente virtual de aprendizagem. 2017. 200f. Tese (Doutorado) - Universidade Católica de Petrópolis, Programa de Pós-Graduação em Educação, Petrópolis, 2017. Disponível em: https://sucupira.capes.gov.br/sucupira/public/consultas/coleta/trabalhoConclusao/viewTrabalh oConclusao.jsf?popup=true\&id trabalho=5062867. Acesso em: 28 jan. 2021.

OLIVEIRA, A.; SCHERER, S. Formação continuada de professores de matemática: tecnologias, interação e aprendizagem. In: VI Sesemat - Seminário Sul-Mato-Grossense de Pesquisa em Educação Matemática. Anais do VI Sesemat - Seminário Sul-Mato-Grossense de Pesquisa em Educação Matemática, 2012. Disponível em: https://periodicos.ufms.br/index.php/sesemat/issue/view/238 . Acesso em: 28 jan. 2021.

PRIMO, Alex. Interação mediada por computador: comunicação, cibercultura, cognição. 2 ed. Porto Alegre: Sulina, 2008.

ROCHA, A. K. de O. A programação de computadores como meio para integrar diferentes conhecimentos: uma experiência com professores de Matemática. 2015. 219f. Tese (Doutorado) - Universidade Anhanguera de São Paulo, Programa de Pós-Graduação em Educação Matemática, São Paulo, 2015. Disponível em:

https://repositorio.pgsskroton.com/handle/123456789/3468. Acesso em: 28 jan. 2021.

SÁ, R. A. de. Educação à Distância: estudo exploratório e analítico de graduação na área de formação de professores. 422 p. Tese (Doutorado) - Universidade Estadual de Campinas, Faculdade de Educação, Programa de Pós-Graduação em Educação, Campinas, 2007. Disponível em: http://repositorio.unicamp.br/jspui/handle/REPOSIP/251842 Acesso em: 28 jan. 2021.

SALES, R. G. O Ambiente Virtual de Aprendizagem e sua incorporação na UFMT: em foco os cursos de Ciências Biológicas. 2017. 80f. Dissertação (Mestrado) - Universidade Federal de Mato Grosso, Programa de Pós-Graduação em Educação, Cuiabá, 2017. Disponível em: https://ri.ufmt.br/handle/1/1948. Acesso em: 28 jan. 2021.

SANTOS, E. O. dos. Educação online: Cibercultura e pesquisa-formação na prática docente. 2005. 351f. Tese (Doutorado) - Universidade Federal da Bahia, Programa de Pós-Graduação em Educação, Salvador, 2005. Disponível em:

http://www.repositorio.ufba.br/ri/handle/ri/11800. Acesso em: 26 jan. 2021.

SASSI, S. B. O Ambiente Virtual de Aprendizagem como apoio ao Ensino Presencial de Matemática: uma proposta com design instrucional. 2016. 215f. Dissertação (Mestrado) Universidade Federal do Mato Grosso, Programa de Pós-Graduação em Educação, Cuiabá, 2016. Disponível em: http://ri.ufmt.br/handle/1/1040. Acesso em: 26 jan. 2021.

SAUSEN, S. Os recursos de ambientes virtuais no ensino presencial: uma experiência com alunos de um curso de licenciatura em matemática. 2011. 216 f. Dissertação (Mestrado) - Universidade Federal do Paraná, Programa de Pós-Graduação em Educação, Curitiba, 2011. Disponível em: https://hdl.handle.net/1884/65265. Acesso em: 26 jan. 2021. 
SCHERER, S. Uma Estética Possível para a Educação Bimodal: Aprendizagem e Comunicação em Ambientes Presenciais e Virtuais. 2005. 241 p. Tese (Doutorado) Pontifícia Universidade Católica, Programa de Pós-Graduação em Educação: Currículo, São Paulo, 2005. Disponível em: https://tede2.pucsp.br/handle/handle/9942. Acesso em: 26 jan. 2021.

SOEK, A. M.; HARACEMIV, S. M. C. Os desafios da complexidade da formação docente na Educação a Distância. In: Complexidade e Educação: diálogos epistemológicos transformadores. GUÉRIOS, E.; PISKE, F. da H. R.; SOEK, A. M.; SILVA, E. J. (Orgs.). Curitiba, PR: CRV, 2017.

TARDIF, M.; LESSARD, C.; LAHAYE, L. Os professores face ao saber: esboço de uma problemática do saber docente. Revista Teoria e Educação, Porto Alegre, n. 4, p. 215-233, 1991. Disponível em:

https://edisciplinas.usp.br/pluginfile.php/2075923/mod resource/content/1/Textocomplementar-Aula-4-TARDIFF-LESSARD-LAHAYE-1991.pdf. Acesso em: 26 jan. 2021.

\section{NOTAS}

\section{AGRADECIMENTOS}

Não se aplica.

\section{FINANCIAMENTO}

Não se aplica.

\section{CONTRIBUIÇÕES DE AUTORIA}

Resumo/Abstract/Resumen: Sandra Sausen e Ettiène Cordeiro Guérios

Introdução: Sandra Sausen e Ettiène Cordeiro Guérios

Referencial teórico: Sandra Sausen e Ettiène Cordeiro Guérios

Análise de dados: Sandra Sausen e Ettiène Cordeiro Guérios

Discussão dos resultados: Sandra Sausen e Ettiène Cordeiro Guérios

Conclusão e considerações finais: Sandra Sausen e Ettiène Cordeiro Guérios

Referências: Sandra Sausen e Ettiène Cordeiro Guérios

Revisão do manuscrito: Sandra Sausen e Ettiène Cordeiro Guérios

Aprovação da versão final publicada: Sandra Sausen e Ettiène Cordeiro Guérios

Obs.: Revisões: Ressílvia Aparecida Steniski (Abstract); Mara Regina Gregório Kusma (Resumen); e, Juliana Pessi Mayorca (de linguagem).

\section{CONFLITOS DE INTERESSE}

Os autores declararam não haver nenhum conflito de interesse de ordem pessoal, comercial, acadêmico, político e financeiro referente a este manuscrito.

\section{DISPONIBILIDADE DE DADOS DE PESQUISA}

O conjunto de dados que dá suporte aos resultados da pesquisa está publicado no artigo.

\section{CONSENTIMENTO DE USO DE IMAGEM}

Não se aplica.

\section{APROVAÇÃO DE COMITÊ DE ÉTICA EM PESQUISA \\ Não se aplica.}


COMO CITAR - ABNT

SAUSEN, Sandra. GUÉRIOS, Ettiène Cordeiro. Presencial e virtual: o extrapolar de fronteiras físicas e digitais. REAMEC - Rede Amazônica de Educação em Ciências e Matemática. Cuiabá, v. 9, n. 1, e21029, janeiroabril, 2021. https://doi.org/10.26571/reamec.v9i1.11777

\section{COMO CITAR - APA}

Sausen, S. \& Guérios, E. C. (2021). Presencial e virtual: o extrapolar de fronteiras físicas e digitais. REAMEC Rede Amazônica de Educação em Ciências e Matemática, 9(3), e21029. https://doi.org/10.26571/reamec.v9i1.11777

\section{LICENÇA DE USO}

Licenciado sob a Licença Creative Commons Attribution-NonCommercial 4.0 International (CC BY-NC 4.0). Esta licença permite compartilhar, copiar, redistribuir o manuscrito em qualquer meio ou formato. Além disso, permite adaptar, remixar, transformar e construir sobre o material, desde que seja atribuído o devido crédito de autoria e publicação inicial neste periódico.

\section{DIREITOS AUTORAIS}

Os direitos autorais são mantidos pelos autores, os quais concedem à Revista REAMEC - Rede Amazônica de Educação em Ciências e Matemática - os direitos exclusivos de primeira publicação. Os autores não serão remunerados pela publicação de trabalhos neste periódico. Os autores têm autorização para assumir contratos adicionais, separadamente, para distribuição não exclusiva da versão do trabalho publicada neste periódico (ex.: publicar em repositório institucional, em site pessoal, publicar uma tradução, ou como capítulo de livro), com reconhecimento de autoria e publicação inicial neste periódico. Os editores da Revista têm o direito de proceder a ajustes textuais e de adequação às normas da publicação.

\section{PUBLISHER}

Universidade Federal de Mato Grosso. Programa de Pós-graduação em Educação em Ciências e Matemática (PPGECEM) da Rede Amazônica de Educação em Ciências e Matemática (REAMEC). Publicação no Portal de Periódicos UFMT. As ideias expressadas neste artigo são de responsabilidade de seus autores, não representando, necessariamente, a opinião dos editores ou da referida universidade.

\section{EDITOR}

\section{Dailson Evangelista Costa (D) 9}

\section{HISTÓRICO}

Submetido: 02 de fevereiro de 2021.

Aprovado: 16 de março de 2021.

Publicado: 12 de abril de 2021. 